\title{
Welcome Back!
}

We hope you are finding our content practical, yet providing a vista toward the fast approaching future in US healthcare.

This issue, read Vikram Dhillon's article on electronic health records....and of the opportunities and challenges ahead in deploying blockchains for digital health.

Monica Leslie and Rehan Virani are back this issue elaborating a new perspective on CCM programs and understanding the value-generating opportunities resulting from the use of telehealth.

We are proud to welcome our newest editorial board member, Dr. Dirk G. Schroeder. $\mathrm{He}$ is the Chief Health Officer and Co-Founder at HolaDoctor, Inc (www.holadoctor.net), and leader of the multicultural growth and communications solutions to the U.S. healthcare industry.

We invite you to spend time reading or listening to TMT'S June content. You will find a new partner aboard, the Pharmacy Podcast show. This issue listen to how technologies in the pharmacy industry and health system pharmacies, including consultations and medication therapy management, are impacting telehealth.

Feel free to relay your comments. Our April issue has been archived under the Past Issues tab.

As an aside, our passion is to provide evidence-based data for our audience.

Consider submitting your research or viewpoint papers to us. For more information, contact us here.

See you in August...

Best,

Tory Cenaj

Founder and Publisher: Telehealth and Medicine Today ${ }^{\mathrm{TM}}$ 